\section{FRI0304 SERUM IGG-UNDERGALACTOSYLATION PROFILES REFLECT CUMULATIVE EXPOSURE TO SYSTEMIC INFLAMMATION IN SPONDYLOARTHRITIS PATIENTS}

A. S. De Craemer ${ }^{1,2}$, Z. Lukasik ${ }^{3}$, L. Meuris ${ }^{4}$, L. Deroo ${ }^{1,2}$, T. Renson ${ }^{1,2}$, M. De Hooge $^{1,2}$, P. Carron ${ }^{1,2}$, A. Van Hecke ${ }^{4,5}$, N. Callewaert ${ }^{4,5}$, F. Van den Bosch ${ }^{1,2}$, D. Elewaut ${ }^{1,2}$ on behalf of the Be-Giant Consortium. ${ }^{1}$ Ghent University Hospital, Rheumatology, Gent, Belgium; ${ }^{2}$ VIB, Inflammation Research Center, Gent, Belgium; ${ }^{3}$ Medical University of Lodz, tódź, Poland; ${ }^{4}$ VIB, Center for Medical Biotechnology, Gent, Belgium; ${ }^{5}$ Ghent University, Department of Biochemistry and Microbiology, Gent, Belgium

Background: Inflammation in spondyloarthritis $(\mathrm{SpA})$ is often not reflected by elevated acute phase reactants such as C-reactive protein (CRP) or erythrocyte sedimentation rate $(E S R)$. It has been shown that IgG glycosylation patterns are subject to specific alterations (i.e. undergalactosylation) in chronic inflammatory diseases. Since these changes only occur in persistent inflammatory processes, lasting at least one to two $t_{1 / 2}$ of $\lg G$ (24 days), it was hypothesized that IgG-glycan profiles could serve as a surrogate marker for chronic inflammation in SpA patients.

Objectives: To assess the value of serum IgG-undergalactosylation in $\mathrm{SpA}$ patients in relation to outcome measures for disease activity, determined by patient reported outcomes, serum inflammatory markers and imaging outcomes.

Methods: Serum samples were obtained from SpA patients at the baseline visit of Be-Giant: a Belgian observational cohort including SpA patients who fulfill the ASAS classification criteria for axial or peripheral SpA. IgG Fc N-glycans were released directly in whole serum by endo- $\beta$ - $\mathrm{N}$-acetyl-glucosaminidase from Streptococcus pyogenes (EndoS), fluorescently labeled with ATPS and analyzed by capillary electrophoresis, rendering glycan profiles with six peaks (Figure 1). Relative peak heights were combined in the undergalactosylation score (UGS), capturing the relative upregulation of non-galactosylated glycans normalized to the total peak height (1). Baseline radiographs (X-SIJ) and magnetic resonance images (MRI) of the sacroiliac joints (SIJ) were assessed by three calibrated readers for sacroiliitis (fulfillment of the modified New York criteria; grading 0 to 4 per SIJ) and for inflammatory lesions according to the Spondyloarthritis Research Consortium of Canada (SPARCC) method (score from 0 -72) respectively. Grades and inflammatory lesions that were seen by at least 2 readers were used for further analysis.

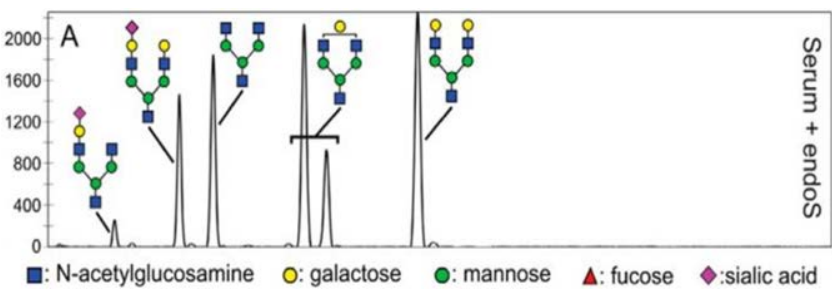

Figure 1. Example of a serum IgG-specific glycan profile. Adapted from (1), with permission.

Results: Glycan profiles were obtained from 376 SpA patients; UGS was scaled $($ mean $=0, S D=1)$ for further analysis. UGS was independently associated with ASDAS-CRP $\left(\beta_{1}=0.15,95 \% \mathrm{Cl} 0.04-0.26, p=0.006\right)$ and BASFI $\left(\beta_{1}=\right.$ $0.44,95 \% \mathrm{Cl} 0.16-0.72, \mathrm{p}=0.002)$ but not with BASDAI $\left(\beta_{1}=0.12,95 \% \mathrm{Cl}\right.$ $-0.13-0.38, p=0.34)$. UGS showed a weak to moderate correlation with CRP $\left(R_{s}=0.30, p<0.001\right)$ and ESR $\left(R_{s}=0.27, p<0.001\right)$. In axial SpA, UGS was significantly higher in patients with ankylosing spondylitis compared to non-radiographic axial $\mathrm{SpA}(\mathrm{OR}=2.41,95 \% \mathrm{Cl} 1.60-3.73, \mathrm{p}<0.001)$ and showed an independent association with the total grading of the SIJ $\left(\beta_{1}=0.44,95 \% \mathrm{Cl} 0.09\right.$ $-0.80, p=0.01$, Figure 2$)$ and SPARCC score $\left(\beta_{1}=2.64,95 \% \mathrm{Cl} 0.98-4.31, \mathrm{p}=\right.$ 0.002). All models were adjusted for age, gender, BMI, CRP, anti-TNF treatment and symptom duration.

Conclusion: This study shows and independent association of serum IgG undergalactosylation with disease activity and functional impairment in SpA patients. Moreover, UGS was significantly higher in advanced compared to early-stage axial disease and therefore may reflect the cumulative exposure to systemic inflammation.

References:

[1] Vanderschaeghe D, Meuris L, Raes T, et al. Endoglycosidase S Enables a Highly Simplified Clinical Chemistry Procedure for Direct Assessment of Serum IgG Undergalactosylation in Chronic Inflammatory Disease. Mol Cell Proteomics. 2018;17(12):2508-17.

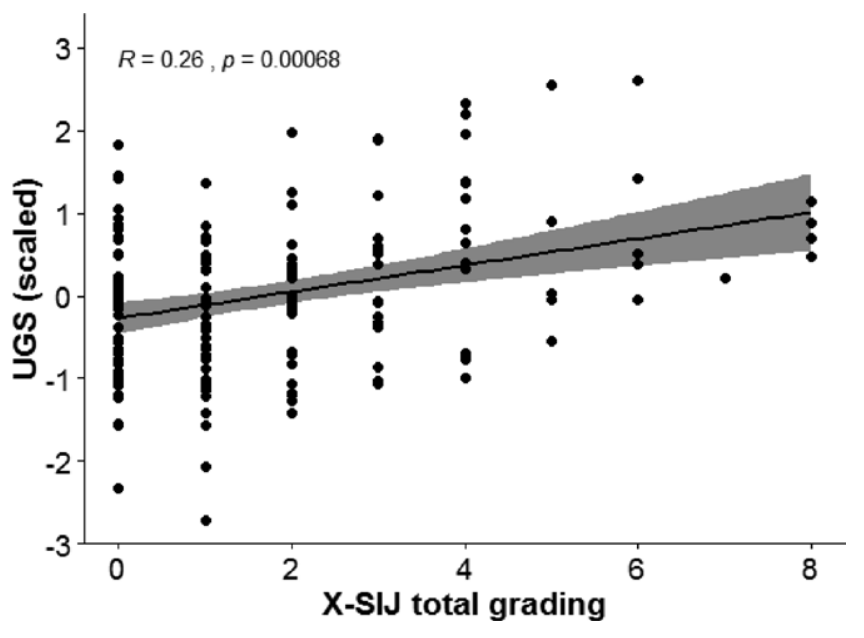

Figure 2. Correlation between UGS and X-SIJ total grading of sacroilitis. R = Spearman's correlation coefficient.

Disclosure of Interests: Ann-Sophie De Craemer: None declared, Zuzanna Lukasik: None declared, Leander Meuris: None declared, Liselotte Deroo: None declared, Thomas Renson: None declared, Manouk de Hooge: None declared, Philippe Carron: None declared, Annelies Van Hecke: None declared, Nico Callewaert: None declared, Filip van den Bosch Consultant of: AbbVie, Celgene Corporation, Eli Lilly, Galapagos, Janssen, Novartis, Pfizer, and UCB, Speakers bureau: AbbVie, Celgene Corporation, Eli Lilly, Galapagos, Janssen, Novartis, Pfizer, and UCB, Dirk Elewaut: None declared DOI: 10.1136/annrheumdis-2020-eular.3365

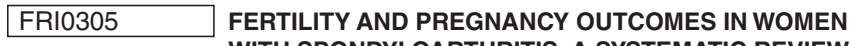 WITH SPONDYLOARTHRITIS: A SYSTEMATIC REVIEW AND META-ANALYSIS}

S. Hamroun ${ }^{1}$, A. Hamroun ${ }^{2}$, J. J. Bigna ${ }^{3}$, E. Allado ${ }^{4}$, F. Förger ${ }^{5}$, A. Moltó ${ }^{6}$.

${ }^{1}$ Rheumatology Department, Cochin Hospital, Paris, France; ${ }^{2}$ Lille University, Faculty of Medicine, Lille, France; ${ }^{3}$ School of Public Health, Faculty of Medicine, University of Paris Sud XI, Le Kremlin Bicêtre, France; ${ }^{4}$ Rheumatology Department, University Hospital of Nancy, Nancy, France; ${ }^{5}$ University Hospital and University of Bern, Bern, Switzerland; ${ }^{6}$ INSERM U-1153, University of Paris, Paris, France

Background: Women with spondyloarthritis $(\mathrm{SpA})$ are often affected by the disease during their reproductive years ${ }^{1}$. However, little is known about the impact of the disease and its treatments on fertility and pregnancy outcomes, as well as the effect of pregnancy itself on disease activity ${ }^{2}$.

Objectives: The aim of the study was to determine the effects of spondyloarthritis on fertility and pregnancy outcomes in women with SpA.

Methods: We searched Pubmed, Embase, and Web of Science until 1 November 2019, without any language restriction. All studies assessing fertility, pregnancy outcomes and disease activity during pregnancy in women with spondyloarthritis (axial SpA (axSpA) but also peripheral SpA, including psoriatic arthritis ( $P s A)$ ) were eligible. The heterogeneity between studies was quantified $\left(I^{2}\right)$, and multiple meta-regressions were carried out to identify potential sources of heterogeneity. In case $\mathrm{I}^{2}$ was $<50 \%$, a random-effects model was used to pool the available data. Prevalence of events was described as percentages. The odds ratio (OR) and corresponding $95 \%$ confidence interval $(\mathrm{Cl})$ were used to assess the associations between the disease and the pregnancy outcomes.

Results: Within 4397 eligible studies, 21 articles fulfilling the selection criteria were included in the review, assessing overall 3306 patients (2578 with axSpA and 728 with PsA) and 4104 pregnancies compared to 42248 healthy controls (in 11 studies with a control group). Among the included studies, the risk of bias was evaluated as high, moderate and low in respectively 12, 1 and 8 studies. Regarding pregnancy outcomes, several studies report an increased risk of preterm birth, small for gestational age (pooled OR 2,05, [1,09-3,89], $12=5,8 \%$ in axSpA) and caesarean section (pooled OR 1,77 [1,45-2,17], $I 2=27,5 \%$ in axSpA and pooled OR $1,47[1,22-1,76], I 2=0,0 \%$ in PsA), without any other unfavourable pregnancy outcome (miscarriage, stillbirth, gestational diabetes or preeclampsia). Further analysis found a significant higher risk for elective caesarean (pooled OR 2,64, [1,92-3,62], I2=0,0\% in axSpA and pooled OR $1,47,[1,15-1,88], 12=0,0 \%$ in PsA), without increased risk for emergency caesarean. There was no substantial heterogeneity in the majority of meta-analyses. 
Conclusion: Although based on observational data, this work is to our knowledge, the first systematic review and meta-analysis concerned with this subject. SpA and PsA seem to be associated with an increased risk of preterm birth, small for gestational age and elective caesarean section. The analysis of the impact of pregnancy on disease activity in this setting is currently ongoing. References:

[1] Van den Brandt S. Arthritis Res Ther 2017;19(1):64

[2] Ursin K. Rheumatology. 201;57(6):1064-1071.

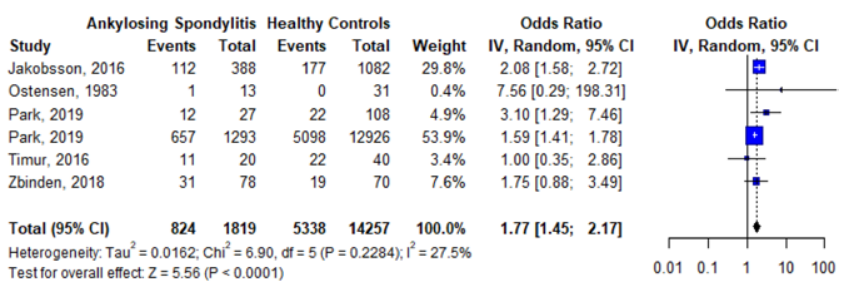

Fig. 1. Association between caesarean section and axSpA

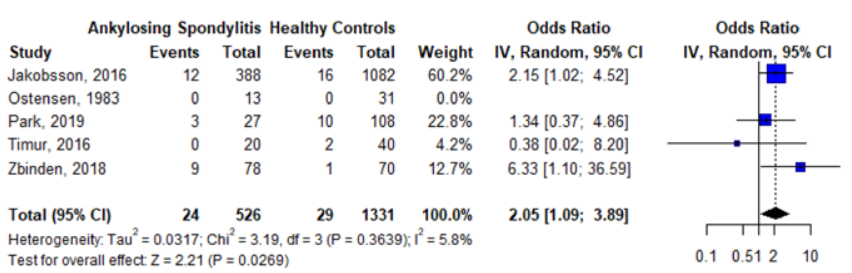

Fig. 2. Association between small for gestational age and axSpA

Disclosure of Interests: SABRINA HAMROUN: None declared, Aghilès Hamroun: None declared, Jean Joël Bigna: None declared, Edem Allado: None declared, Frauke Förger Grant/research support from: Unrestricted grant from UCB, Consultant of: UCB, GSK, Roche, Speakers bureau: UCB, GSK, Anna Moltó Grant/research support from: Pfizer, UCB, Consultant of: Abbvie, BMS, MSD, Novartis, Pfizer, UCB

DOI: 10.1136/annrheumdis-2020-eular.4357

\section{FRI0306 WOMEN WITH AXIAL SPONDYLOARTHRITIS HAVE COMPARABLE RATES OF COMPLICATIONS IN PREGNANCY TO WOMEN IN THE GENERAL POPULATION BUT MORE CAESAREAN DELIVERIES: RESULTS FROM NATIONWIDE CLAIMS DATA}

I. Redeker ${ }^{1}$, A. Strangfeld ${ }^{1}$, U. Marschall ${ }^{2}$, A. Zink ${ }^{1,3}$, X. Baraliakos ${ }^{4} .{ }^{1}$ German Rheumatism Research Centre, Berlin, Germany; ${ }^{2}$ BARMER Institute for Health Systems Research, Wuppertal, Germany; ${ }^{3}$ Charité - Universitätsmedizin Berlin, Berlin, Germany; ${ }^{4}$ Rheumazentrum Ruhrgebiet, Herne, Germany

Background: In contrast to other rheumatic inflammatory diseases, studies on pregnancy outcomes in axial spondyloarthritis (axSpA) are scarce, despite its onset in early adulthood affecting women in their reproductive years.

Objectives: To investigate maternal and infant pregnancy outcomes among women with axSpA compared with population-based controls.

Methods: Taking advantage of a large health insurance dataset, comprising the period $2006-2018$, maternal and infant pregnancy outcomes and delivery outcomes of women with axSpA were assessed and compared with population-based controls (matched by maternal age and calendar year of birth). Odds ratios (ORs) with $95 \%$ confidence intervals (Cls) were calculated using generalised estimating equation analyses.

Results: A total of 611 singleton births among 535 women with axSpA were included in the analysis. The mean age at delivery was 32.5 years. The pharmacological treatment within 12 months prior to and after conception is illustrated in the Figure. Infants of women with axSpA were only slightly more often preterm $(5.2 \%$ vs $4.7 \%)$ and small-for-gestational-age (1.6\% vs $1.1 \%)$ than infants of matched population-based controls, respectively. Caesarean section was performed in $36 \%$ of deliveries among women with axSpA compared with $29.5 \%$ in population-based controls, resulting in a significantly increased risk for receiving caesarean section (OR 1.35; 95\% Cl 1.06-1.73) (Table). The occurrence of pre-eclampsia, preterm birth, and small-for-gestational-age was moderately higher, but not significantly increased, among women with axSpA as compared to population-based controls.

Conclusion: Women with axSpA had no significantly increased risks for adverse maternal or infant pregnancy outcomes compared to non-axSpA women.
However, a significantly increased risk for receiving caesarean section and a tendency for a higher number of preterm deliveries and of small-for-gestational-age infants was observed in women with axSpA.

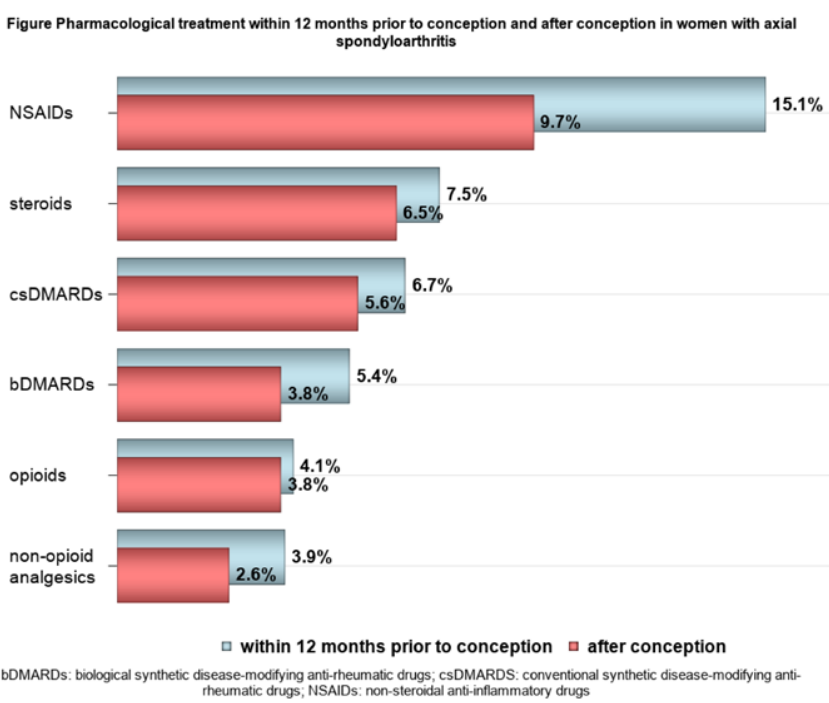

Table. Prevalences and odds ratios with $95 \%$ confidence intervals for adverse pregnancy outcomes

\begin{tabular}{lccc}
\hline & $\begin{array}{c}\text { Pregnancies in } \\
\text { women with axSpA population-based controls } \\
\mathrm{N}=611\end{array}$ & $\begin{array}{c}\text { Pregnancies in } \\
\mathrm{N}=611\end{array}$ & $\begin{array}{c}\text { Odds Ratio } \\
(95 \% \mathrm{Cl})\end{array}$ \\
\hline Preterm birth (< week 37) & $5.2 \%(32)$ & $4.7 \%(29)$ & $1.11(0.66,1.85)$ \\
Gestational week 28-36 & $4.9 \%(30)$ & $4.7 \%(29)$ & $1.03(0.61,1.75)$ \\
Gestational week <28 & $0.3 \%(2)$ & $0.2 \%(1)$ & $2.01(0.18,22.18)$ \\
Small for gestational age & $1.6 \%(10)$ & $1.1 \%(7)$ & $1.43(0.54,3.79)$ \\
Low birth weight $(<2500 \mathrm{~g})$ & $2.8 \%(17)$ & $2.6 \%(16)$ & $1.06(0.53,2.13)$ \\
Exceptionally large baby & $1.1 \%(7)$ & $0.2 \%(1)$ & $7.07(0.87,57.63)$ \\
(birth weight $\geq 4500 \mathrm{~g})$ & & & \\
Pre-eclampsia & $7.5 \%(46)$ & $6.4 \%(39)$ & $1.21(0.78,1.90)$ \\
Assisted vaginal delivery & $4.3 \%(26)$ & $3.1 \%(19)$ & $1.39(0.76,2.56)$ \\
Caesarean section & $36.0 \%(220)$ & $29.5 \%(180)$ & $1.35(1.06,1.73)$ \\
\end{tabular}

axSpA, axial Spondyloarthritis; $\mathrm{Cl}$, confidence interval.

Acknowledgments: We would like to thank the BARMER Statutory Health Insurance for providing data for this study.

Disclosure of Interests: Imke Redeker: None declared, Anja Strangfeld Speakers bureau: AbbVie, BMS, Pfizer, Roche, Sanofi-Aventis, Ursula Marschall: None declared, Angela Zink Speakers bureau: AbbVie, Amgen, BMS, Gilead, Hexal, Janssen, Lilly, MSD, Pfizer, Roche, Sanofi Aventis, UCB, Xenofon Baraliakos Grant/research support from: Grant/research support from: AbbVie, BMS, Celgene, Chugai, Merck, Novartis, Pfizer, UCB and Werfen, Consultant of: AbbVie, BMS, Celgene, Chugai, Merck, Novartis, Pfizer, UCB and Werfen, Speakers bureau: AbbVie, BMS, Celgene, Chugai, Merck, Novartis, Pfizer, UCB and Werfen DOI: 10.1136/annrheumdis-2020-eular.5241

\section{FRI0307 DETERMINANTS OF PATIENT-PHYSICIAN DISCORDANCE IN GLOBAL ASSESSMENT IN SPONDYLOARTHRITIS}

S. Azevedo ${ }^{1}$, F. Guimarães ${ }^{1}$, D. Almeida ${ }^{2}$, D. Faria ${ }^{1}$, J. Silva ${ }^{1}$, J. Rodrigues ${ }^{1}$, D. Peixoto ${ }^{1}$, S. Alcino ${ }^{1}$, J. Tavares-Costa ${ }^{1}$, C. Afonso', F. Teixeira ${ }^{1} .{ }^{1}$ Unidade Local de Saúde do Alto Minho, Rheumatology Department, Ponte de Lima, Portugal; ${ }^{2}$ Hospital de Braga, Rheumatology Department, Braga, Portugal

Background: Patient's Global Assessment of Disease Activity (PtGA) and Physician's Global Assessment of Disease Activity (PhGA) are important measures in the evaluation of patients with Spondyloarthritis $(\mathrm{SpA})$, but often provide discordant results. ${ }^{1}$ Both PtGA and PhGA are assessed as part of ankylosing spondylitis disease activity score (ASDAS), that is a measure of axial SpA disease activity endorsed by the Assessment of SpA International Society (ASAS) and Outcome Measures in Rheumatology. ${ }^{2,3}$ In peripheral SpA, although there are no formally validated indexes, the American College of Rheumatology (ACR) and Disease Activity Score 28 (DAS 28) response criteria have shown reliable discriminant characteristics and both include PtGA and PhGA. ${ }^{3}$ The lack 